\title{
Bromide impairs the circadian clock and glycolytic homeostasis via disruption of autophagy in rat $\mathrm{H} 9 \mathrm{C} 2$ cardiomyocytes
}

\author{
Yicheng Jiang ${ }^{\dagger}$, Yang $\mathrm{Gu}^{\dagger}{ }^{\dagger}$ Hai Xu, Xiaoyi Tian, Xuefeng Zhang, Xiaojin Xu, Wenting Yan and Xiwen Zhang ${ }^{*}$
}

\begin{abstract}
Background: Trace elements function as essential cofactors that are involved in various biochemical processes in mammals. Autophagy is vital for nutrient supplement, which is an important Zeitegber for the circadian homeostasis in heart. Here, we considered the possibility that autophagy, as well as the cardiomyocyte clock and glycolysis are interlinked. Detrimental effects were observed when cardiac system is exposed to bromine containing drugs. This study investigated the effects and mechanisms of bromide on the circadian clock and glycolytic metabolism of H9C2 cardiomyocytes.

Results: In the present study, bromide does not affect cell viability and apoptosis of H9C2 cardiomyocytes. Bromide dampens the clock and glycolytic (Hk2 and Pkm2) gene expression rhythmicity in a dose-dependent manner. Additionally, bromide inhibits autophagic process in H9C2 cardiomyocytes. In contrast, rapamycin (an autophagy inducer) dramatically restores the inhibitory effect of $\mathrm{NaBr}$ on the mRNA expression levels of clock genes (Bmal1, Cry 1 and Rora) and glycolytic genes (Hk2 and Pkm2).
\end{abstract}

Conclusions: Our results reveal that bromide represses the clock and glycolytic gene expression patterns, partially through inhibition of autophagy.

Keywords: Bromide, H9C2, Circadian clock, Glycolysis, Autophagy

\section{Background}

Sufficient trace elements play important roles in maintaining our body healthy. Recently, it has been well established that the deficiency of metal ions, such as iron, zinc and copper, leads to various diseases including heart failure, diabetes and bone marrow hematopoiesis [1-3]. Of note, bromine is a unique trace element that possessing negative charge in the biosphere. In the past twentieth century, the environmental doses of bromide increased due to the salt-mining wastes and the degradation products of fumigants, causing an inevitably exposure of bromide for the general population [4]. Hence, as

\footnotetext{
* Correspondence: xiwenzhang123@163.com

†Yicheng Jiang and Yang Gu contributed equally to this work.

The Affiliated Huai'an No.1 People's Hospital of Nanjing Medical University,

No. 1 Huanghe West Road, Huaiyin District, Huai'an 223300, Jiangsu, China
}

a residue in food, the toxicological and physiological evaluations of bromide are raring necessary.

Bromide is widely used in the drug development. For example, triple bromide elixir functions as an adjunctive antiepileptic drug to treat the children whose seizure disorders were intractable to other antiepileptic therapy [5]. Tiotropium bromide $\left(\right.$ Spiriva $\left.^{\circ}\right)$ is a long-term anticholinergic bronchodilator that maintains bronchodilation for at least one day [6]. More importantly, the concentrations of bromide are negatively correlated with the lipids including TG, TC, and HDL-C in the human and rat plasma [6]. Coincidence with these findings, bromide exhibits beneficial effects on the FFA-induced lipid dysregulation in mouse hepatocytes, increasing its possibility in the treatment of metabolic disorders such as hepatic steatosis [7]. All these studies implicate that 
bromide could be developed as a promising drug in the treatment of various diseases. However, the neuromuscular blocking drugs (NMBD), pancuronium bromide shows a short-lasting cardiovascular stimulation after a high-dose injection, indicating the potential detrimental effects of bromide on the cardiac system [8]. Given that bromide penetrates the cell membrane through the chloride channel which is a vital ion channel in the cardiovascular system $[9,10]$, it is of great interest to track the pharmacological evidences of bromide on cardiac system and its underlying mechanisms.

For decades, the circadian clock has been demonstrated to maintain the cardiac homeostasis, such as heart rate and blood pressure [11]. Clinical investigations indicate that circadian disruption in shift workers is associated with increased cardiovascular morbidity and mortality blood pressure variation shift workers [12]. These findings are confirmed by animal studies that cardiomyocyte-specific Bmal1 knockout and Clock mutant mice suffer from age-onset cardiomyopathy, early mortality and sinus bradycardia [13]. On the other hand, to meet energy demands, cardiomyocytes dynamically reprogram fuel and energize their metabolic capacity in response to environmental and physiological cues [14]. Importantly, the substrate availability varies in a 24 -h (hour) day, which directly influences the energy supplement. Collectively, these findings demonstrate a tight link between the circadian clock and homeostasis of the cardiac system. However, in general, the molecular process which integrates the cardiac circadian clock and metabolism in response to various external stimulus, such as bromide, remains unknown. Here, we aimed to investigate the effects of bromide on the $\mathrm{H} 9 \mathrm{C} 2$ cardiomyocyte survival and its circadian physiological homeostasis with the hope of elucidating the mechanism of its cardiovascular medicinal potential.

\section{Results}

\section{Bromide does not affect survival and apoptosis of $\mathrm{H} 9 \mathrm{C} 2$} cardiomyocytes

To investigate the effects of bromide on the cardiomyocytes, we firstly assessed the toxicity of $\mathrm{NaBr}$. As shown in Fig. 1a, CCK-8 analysis demonstrated that $\mathrm{NaBr}$ was not toxic to $\mathrm{H} 9 \mathrm{C} 2$ cardiomyocytes when the concentration was up to $600 \mu \mathrm{M}$. Besides, similar tendency was observed in isolated rat neonatal primary cardiomyocytes when treated with the same doses of $\mathrm{NaBr}$ (Fig. S1). Hence, the doses range from $50 \mu \mathrm{M}$ to $400 \mu \mathrm{M}$ were regarded as safe and were chosen for the subsequent experiments. In addition, bromide did not affect mRNA expression levels of apoptosis-associated factors $\mathrm{Bcl}-2$, Bax and Caspase-3 (Fig. 1b). Consistently, the active form level of Caspase-3 (the cleaved type) was not altered by $\mathrm{NaBr}$ incubation (Fig. 1c and d). These results implied that cell apoptosis was not regulated in response to bromide stimulation.

\section{Bromide dampens clock gene expression in $\mathrm{H} 9 \mathrm{C} 2$ cardiomyocytes}

As shown in Fig. 2a and b, treatment of $\mathrm{NaBr}$ at the doses of $200 \mu \mathrm{M}$ and $400 \mu \mathrm{M}$ robustly inhibited mRNA levels of key clock genes Bmal1, Cry1 and Rora in a dose-dependent manner. In particular, $400 \mu \mathrm{M} \mathrm{NaBr}$ inhibited mRNA levels of Bmal1 by $41.5 \%$, Cry 1 by $59.5 \%$ and Ror $\alpha$ by $43.8 \%$ respectively. The protein expression of these genes showed similar trends in response to $\mathrm{NaBr}$ (Fig. 2a-c). Also, we detected other clock genes expression upon $\mathrm{NaBr}$ treatment in Fig. S2. Of note, serum shock has been demonstrated to induce rhythmic clock gene expression in various cells. Here, in our system, serum shock also resulted in a robust oscillation of clock genes including Bmal1, Cry1 and Ror . etc. (Fig. 2d, $\mathrm{h}$ and l). However, the Per1 did not exhibit an obvious circadian oscillation in $\mathrm{H} 9 \mathrm{C} 2$ cardiomyocytes, which is in consistent with previous findings (Fig. 2f). Notably, $\mathrm{NaBr}$ treatment did not alter the phase of oscillation patterns of clock genes, but dampened the amplitudes at most checked time-points, except for Clock, whose amplitudes was intensified by $\mathrm{NaBr}$ incubation (Fig. 2d-m and Table S1). All these findings suggested the detrimental role of bromide in dampening the circadian clock in $\mathrm{H} 9 \mathrm{C} 2$ cardiomyocytes.

\section{Bromide inhibits glycolytic gene expression in $\mathrm{H} 9 \mathrm{C} 2$ cardiomyocytes}

Given that circadian disruption in cardiomyocytes is closely correlated with the transition of fuel utilization from lipid oxidation to glycolysis [15], it is of great interest to identify the impact of bromide on the glycolysis. Unexpectedly, $\mathrm{NaBr}$ did not increase, however, dose-dependently decreased mRNA expression levels of $H k 2$ and $P k m 2$, which are hallmarks of glycolysis (Fig. 3a). Similar results were obtained in the protein levels of these genes (Fig. 3b and c). In contrast, PPAR $\alpha$, an important transcriptional factor that activates fatty acid $\beta$-oxidation in heart, was not altered upon $\mathrm{NaBr}$ incubation (Fig. 3a-c). Furthermore, serum shock also induced significant oscillation of Hk2, Pkm2 and Ppara mRNAs. However, bromide dampened the amplitudes of $P k m 2$ and Ppara, while leaving $H k 2$ unchanged in both its phase and amplitude, compared to $\mathrm{NaCl}$-treated group (Fig. 3d-f and Table S2). 

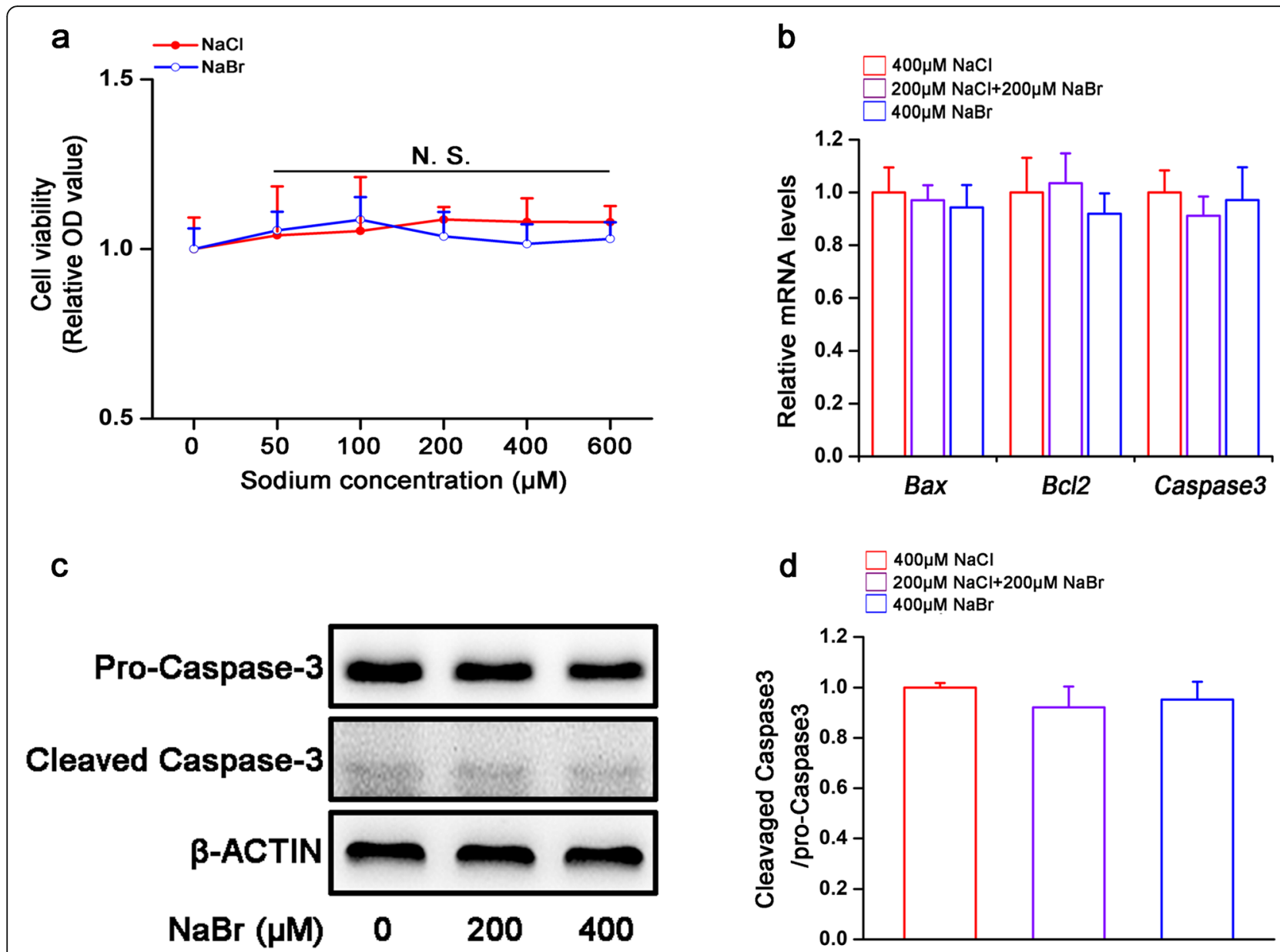

Fig. 1 Bromide does not affect survival and apoptosis of H9C2 cardiomyocytes. $\mathrm{H} 9 \mathrm{C} 2$ cardiomyocytes were treated with $\mathrm{NaBr}$ at indicated doses for $24 \mathrm{~h}$. a Cell viability was assessed by CCK-8 assay. b RT-qPCR analysis of the mRNA expression levels of Bax, Bc/2 and Caspase-3. c Western blot analysis of protein expression levels of Caspase-3. $\mathbf{d}$ Densitometric determinations of (c). $n=3$. All the data were represented as the mean \pm SD. N.S. means no significance

Bromide inhibits autophagy in $\mathrm{H} 9 \mathrm{C} 2$ cardiomyocytes Autophagy is a cellular process that delivers cytosolic components to lysosomes for degradation in response to metabolic stress, such as starvation, to provide a source of nutrients and metabolic fuel [16]. As shown in Fig. 4a and $\mathrm{b}, \mathrm{NaBr}$ dramatically reduced the formation of autophagic puncta evidenced by using adenovirus expressing GFP-RFP-LC3. Coincidence with these findings, $\mathrm{NaBr}$ significantly reduced the LC3 II/LC3 I ratio and mRNA expression levels of Ulk1, Gabarapl1 and Atg5, which are key factors in regulating the autophagosome formation (Fig. 4c). Consistently, the protein expression levels of ULK1 and ATG5 were inhibited by $\mathrm{NaBr}$ in a dose-dependent manner (Fig. $4 \mathrm{~d}$ and e). In addition, serum shock successfully induced rhythmic oscillation of Ulk1, Gabarapl1 and Atg5 genes expression in $\mathrm{H} 9 \mathrm{C} 2$ cells. While the amplitudes of $U l k 1$ and Atg5 were dampened, bromide modestly altered the Gabarapl1 expression oscillation pattern (Fig. 4f-h and Table S3).
Autophagy mediates the inhibitory effect of bromide on the circadian clock and glycolytic gene expression in $\mathrm{H} 9 \mathrm{C} 2$ cardiomyocytes

To investigate the role of autophagy in the regulation of metabolism and autophagy in $\mathrm{H} 9 \mathrm{C} 2$ cardiomyocytes, we incubated cells with $100 \mathrm{nM}$ rapamycin (inhibitor of mTOR activity, as an autophagy inducer). As shown in Fig. $5 \mathrm{a}$ and $\mathrm{b}$, rapamycin restored the inhibitory effect of $\mathrm{NaBr}$ on the mRNA expression levels of clock genes (Bmal1, Cry1 and Ror $\alpha$ ) and glycolytic genes (Hk2 and $P k m 2)$. Also, protein levels of these genes showed similar tendency (Fig. 5c-e). Additionally, the phosphorylation of mTOR protein was slightly inducd by $\mathrm{NaBr}$ treatment (increased to $\sim 1.4$ folds), which was then retarded by rapamycin incubation (Fig. $5 \mathrm{c}$ and $\mathrm{f}$ ), indicating that bromide may inhibit autophagy partially through activating mTOR pathway, and further dampening clock and glycolytic gene expression and their rhythmicity (Fig. 6). In addition, another autophagy inducer, QX77, also 


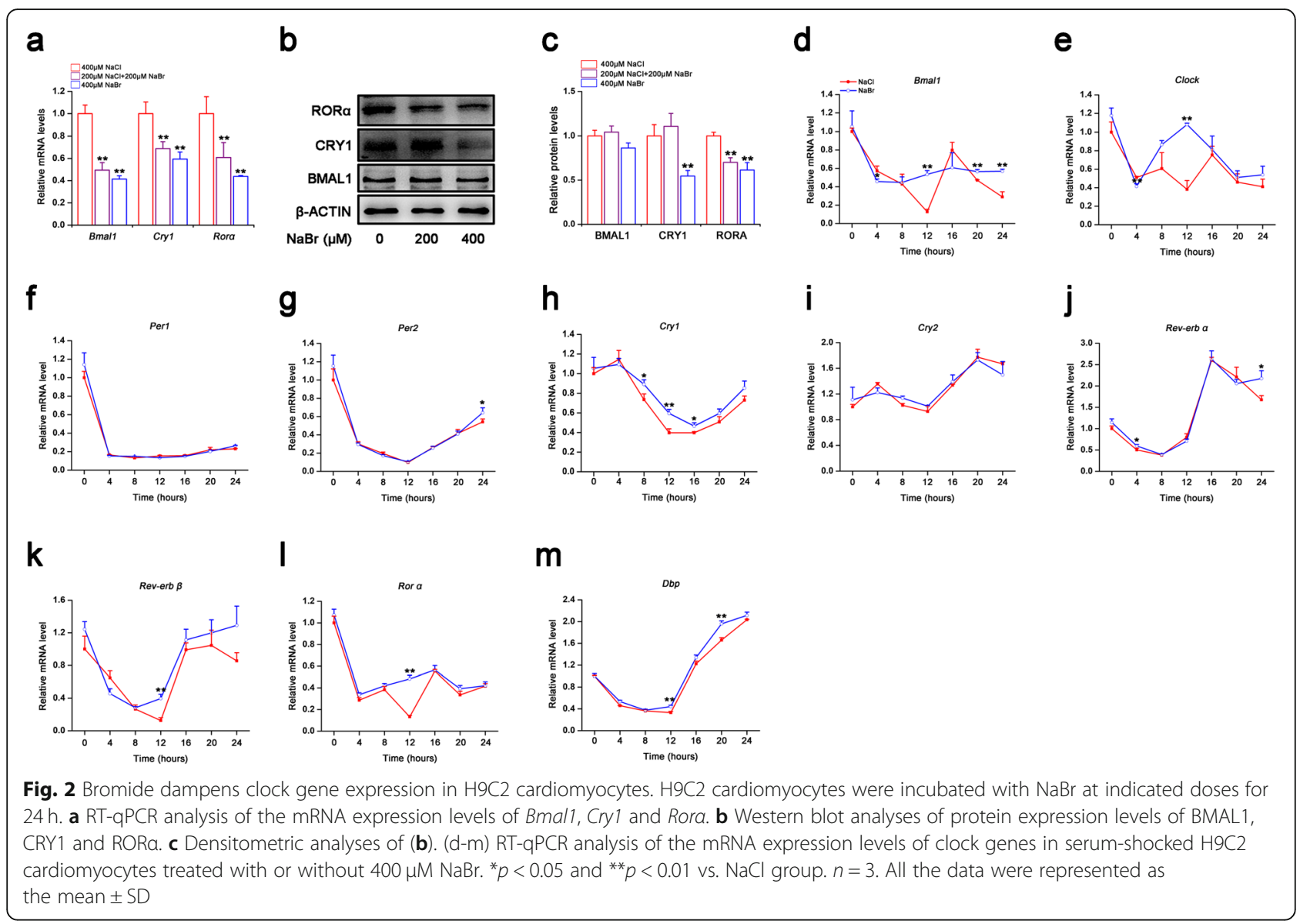

partially reversed the inhibitory effects of $\mathrm{NaBr}$ on the mRNA and protein expression levels of clock genes (Bmal1, Cry1 and Ror $\alpha$ ) and glycolytic genes (Hk2 and Pkm2) (Fig. S3). Given that the autophagy is vital for the maintaining homeostasis in the physiological state, we treated $\mathrm{H} 9 \mathrm{C} 2$ cardiomyocytes with $1 \mu \mathrm{M} \mathrm{H} \mathrm{H}_{2} \mathrm{O}_{2}$ and $400 \mu \mathrm{M} \mathrm{NaBr}$. As shown in Fig. S4, NaBr-treated H9C2 cardiomyocytes are susceptible to $\mathrm{H}_{2} \mathrm{O}_{2}$ stimuli, indicating that the bromide senses the cardiomyocytes to external toxic signals.

\section{Discussion}

As an essential trace element, bromide maintains the redox homeostasis at a serum concentration of $42 \sim$ $61 \mu \mathrm{M}$ in healthy individuals $[17,18]$. Clinically, high dose bromide $(\sim 2.1 \mathrm{mM})$ is used to treat the epilepsy. In 1990s, bromide was thought to be safe with a LD50 at $7000 \mathrm{mg} / \mathrm{kg}$ in rats after acute gavage [19]. However, potential toxicity was observed in the endocrine and reproductive system. Animal experiments revealed that 90day consecutive gavage of high-dose bromide $(14,900$ $\mathrm{mg} / \mathrm{kg}$ ) increased the weights of thyroid adrenal and prostate and induced pathological changes in pituitarium, thyroid, testicle and ovary [19]. More importantly, detrimental effects were observed in cardiac system. For example, bromide-containing drugs pancuronium which is a neuromuscular-blocking drug, induces temporary cardiovascular stimulation, accompanied with rapid upregulations in heart rate, average arterial blood pressure and cardiac output in rats [8]. Rats feed with diet containing $0.8 \%$ brominate vegetable oil (BVO) show enlarged heart and dissolved cardiomyocytes, further inducing the degenerative changes of the myocardium [20]. In our study, we found that bromide did not alter the survival and apoptosis of $\mathrm{H} 9 \mathrm{C} 2$ cardiomyocytes, however, affected the clock and metabolic homeostasis. All these findings indicated the cardiac system are sensitivity to bromide stimulation. Hence, bromide may have potential harmful effect on the cardiac system.

Given the potential toxic effects of bromide on the cardiovascular system, our study was aimed to clarify the impact of bromide on the cardiomyocytes in vitro. In our study, we found that bromide did not alter the cell viability and apoptosis, whereas decreased the autophagy and glycolysis. More importantly, treatment of bromide increased susceptibility to the $\mathrm{H}_{2} \mathrm{O}_{2}$-induced toxicity of $\mathrm{H} 9 \mathrm{C} 2$ cardiomyocytes. 

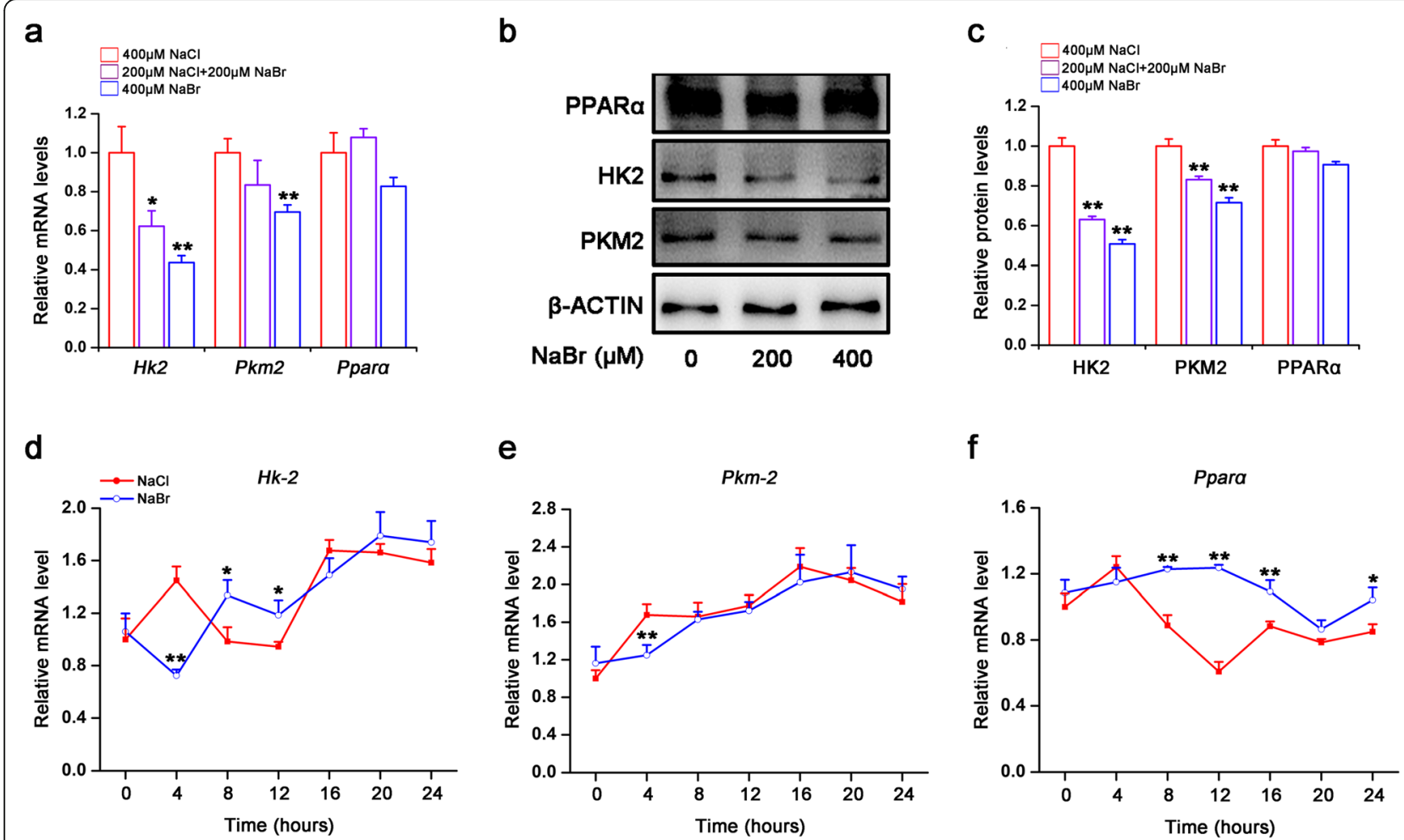

Fig. 3 Bromide inhibits glycolytic gene expression in H9C2 cardiomyocytes. H9C2 cardiomyocytes were treated similar as in Fig. 2a. a RT-qPCR analysis of the mRNA expression levels of Hk2, Pkm2 and Ppara. $\mathbf{b}$ Western blot analysis of protein expression levels of HK2, PKM2 and PPARa. c Densitometric determinations of (b). ( $(\mathrm{d}-\mathrm{f})$ RT-qPCR analysis of the mRNA expression levels of Hk2, Pkm2 and Ppara in serum-shocked H9C2 cardiomyocytes treated with or without $400 \mu \mathrm{M} \mathrm{NaBr} .{ }^{*} p<0.05$ and ${ }^{* *} p<0.01 \mathrm{vs.} \mathrm{NaCl}$ group. $n=3$. All the data were represented as the mean $\pm S D$

On the other hand, chronotherapy and chronopharmacology, which functioned to minimize the drug toxicity and maximize drug efficacy and tolerance, are based on the circadian system. Therefore, we investigated the effect of bromide on the cardiomyocytes' clock to provide experimental and theological basis for the potential effective timing for the bromidecontaining drugs in the future study.

Autophagy is a crucial evolutionarily conserved biological process responsible for eliminating long half-life proteins, damaged organelles and pathogens [21]. Autophagy deficiency has been demonstrated in the pathogenesis of various diseases, such as cancer [22], diabetes [23], and heart failure [24]. Thus, autophagy is vital for cellular homeostasis and nutrient supplement. Given that the nutrient is a important Zeitegber for the circadian homeostasis in heart, here we considered the possibility that autophagy, as well as the cardiomyocyte clock and glycolysis are interlinked. In our study, rapamycin-induced autophagy increased the clock and glycolytic gene expression in response to bromide stimulation, indicating that autophagy indeed integrates the circadian clock and glycolysis in $\mathrm{H} 9 \mathrm{C} 2$ cells. On the other hand, trace elements serve as a pivotal factor to regulate autophagy. For example, the aggravating effect of selenium deficiency on T-2 toxin-induced damage on primary cardiomyocyte results from a reduction of protective autophagy [25]. Therefore, bromide, as a unique trace element, may correlate with autophagic process in the heart. In our study, we found that bromide inhibited autophagic pathway through increasing the phosphorylation of mTOR protein. In contrast, activation of autophagy by rapamycin retarded bromideinduced impairment of the circadian clock and glycolysis in $\mathrm{H} 9 \mathrm{C} 2$ cells, implicating the mediator roles of autophagy in bromide signals. At the molecular level, autophagy induces clock gene CRY1 protein degradation to regulate the liver clock and glucose metabolism [26]. However, rapamycin-induced autophagy transcriptionally increased the CRY1 expression in $\mathrm{H} 9 \mathrm{C} 2$ cells, implying that autophagy regulates CRY1 expression at both posttranscriptional and transcriptional levels according to the tissue specificity. The effects of autophagy in mediating the bromide signals to the circadian clocks and glycolysis of $\mathrm{H} 9 \mathrm{C} 2$ cardiomyocytes were further confirmed by another autophagic activator QX77. 


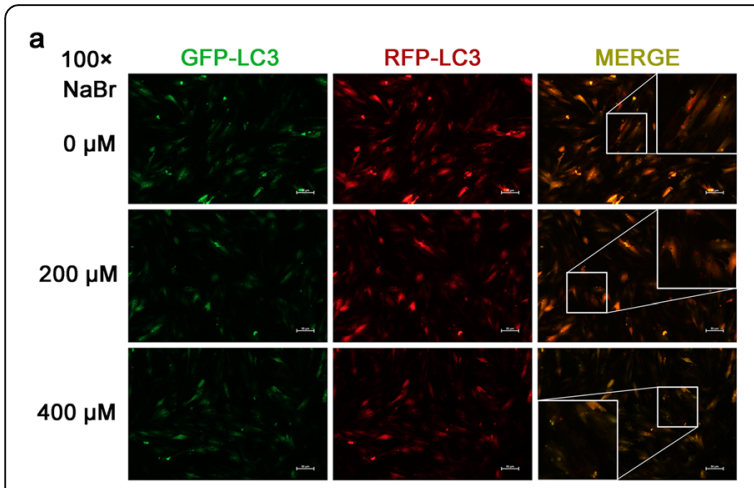

d

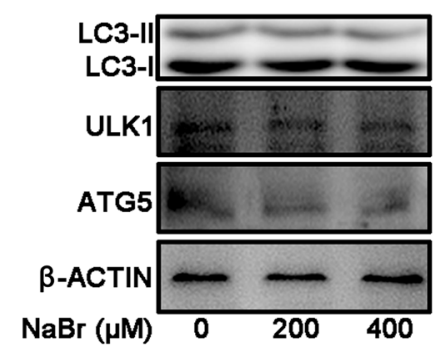

b

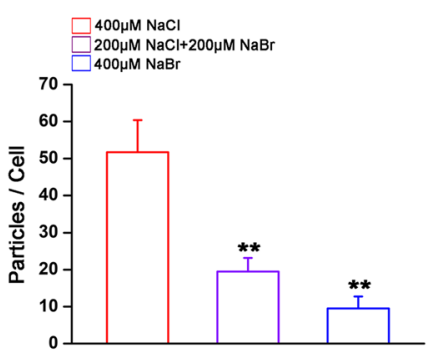

e
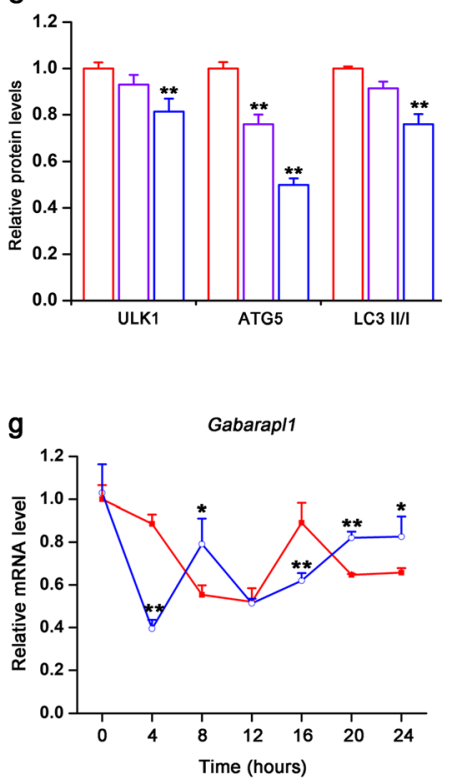

f

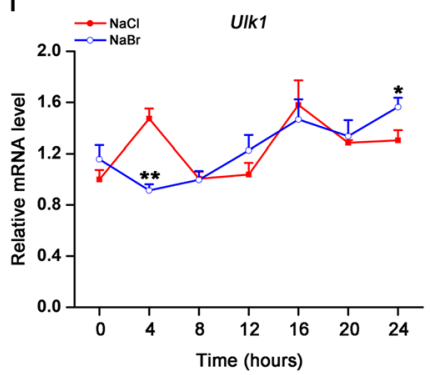

c

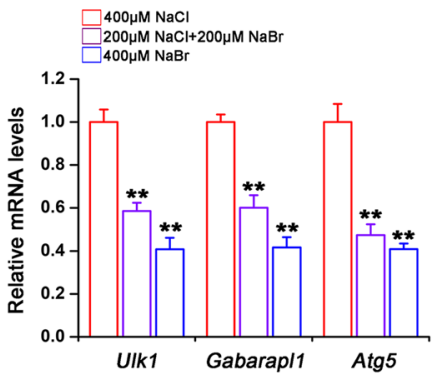

h

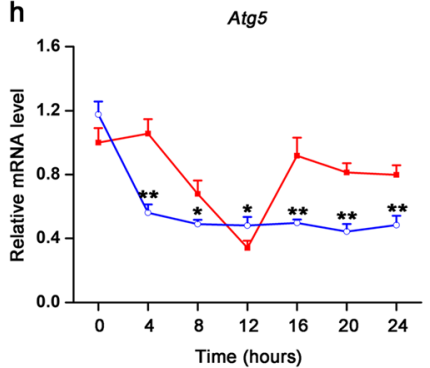

Fig. 4 Bromide inhibits autophagy in H9C2 cardiomyocytes. a H9C2 cardiomyocytes were infected with the adenovirus expressing GFP-RFP-LC3 for $24 \mathrm{~h}$, and followed by NaBr stimulation for another $24 \mathrm{~h}$. Magnification: 100x. H9C2 cardiomyocytes were treated similar as in Fig. 2a. b Analysis of the images from the experiment shown in Fig. 4a. to determine the average number of particles per cell. c RT-qPCR analysis of the mRNA expression levels of Ulk1, Gabarap/1 and Atg5. d, e Western blot and densitometric analyses of protein expression levels of LC3, ULK1 and ATG5. f-h RT-qPCR analysis of the mRNA expression levels of UIk1, Gabarap/1 and Atg5 in serum-shocked H9C2 cardiomyocytes treated with or without $400 \mu \mathrm{M} \mathrm{NaBr} .{ }^{*} p<0.05$ and ${ }^{* *} p<0.01$ vs. NaCl group. $n=3$. All the data were represented as the mean \pm SD

\section{Conclusion}

Our current discoveries demonstrated that the effects of bromide on the circadian and glycolytic gene oscillation in $\mathrm{H} 9 \mathrm{C} 2$ cardiomyocytes, highlighting the mediating roles of autophagy/mTOR in the bromide signal relay. Our findings demonstrated the detrimental, but not toxic effects of high-dose bromide, and suggested that the potential side-effect of bromide-containing drugs on cardiac system. The cardiac safety of bromide should be considered in future drug development.

\section{Methods}

\section{Cell culture}

The rat $\mathrm{H} 9 \mathrm{C} 2$ cardiomyocytes were cultured at $37^{\circ} \mathrm{C}$ and $5 \% \mathrm{CO}_{2}$ in Dulbecco's Modified Eagle Medium (DMEM, high glucose, Gibco-Invitrogen, Carlsbad,
USA), supplemented with $1 \%$ antibiotic-antimycotic (10, $000 \mathrm{U} / \mathrm{mL}$ of penicillin, $10,000 \mathrm{mg} / \mathrm{mL}$ of streptomycin) and $10 \%$ fetal bovine serum (FBS, Gibco-Invitrogen), and were used between passages 15 to 25 . To examine the autophagic status in response to bromide stimulation, we infected the cells with the adenovirus expressing GFP-RFP-LC3 for 24h (hours), and treated with bromide or vehicle (equal molar sodium chloride) for another $24 \mathrm{~h}$. The GFP-RFP-LC3-positive cells were examined by a Nikon fluorescence microscope (ECLIPSE, Ts2R-FL). Rat neonatal primary cardiomyocytes were isolated from the ventricles of Wistar rats aged $1-10$ days $(n=10$, purchased from Model Animal Research Center of Nanjing University, China) as previously described [27]. All animal procedures in this research conform to the Guide for the Care and Use of Laboratory Animals published 


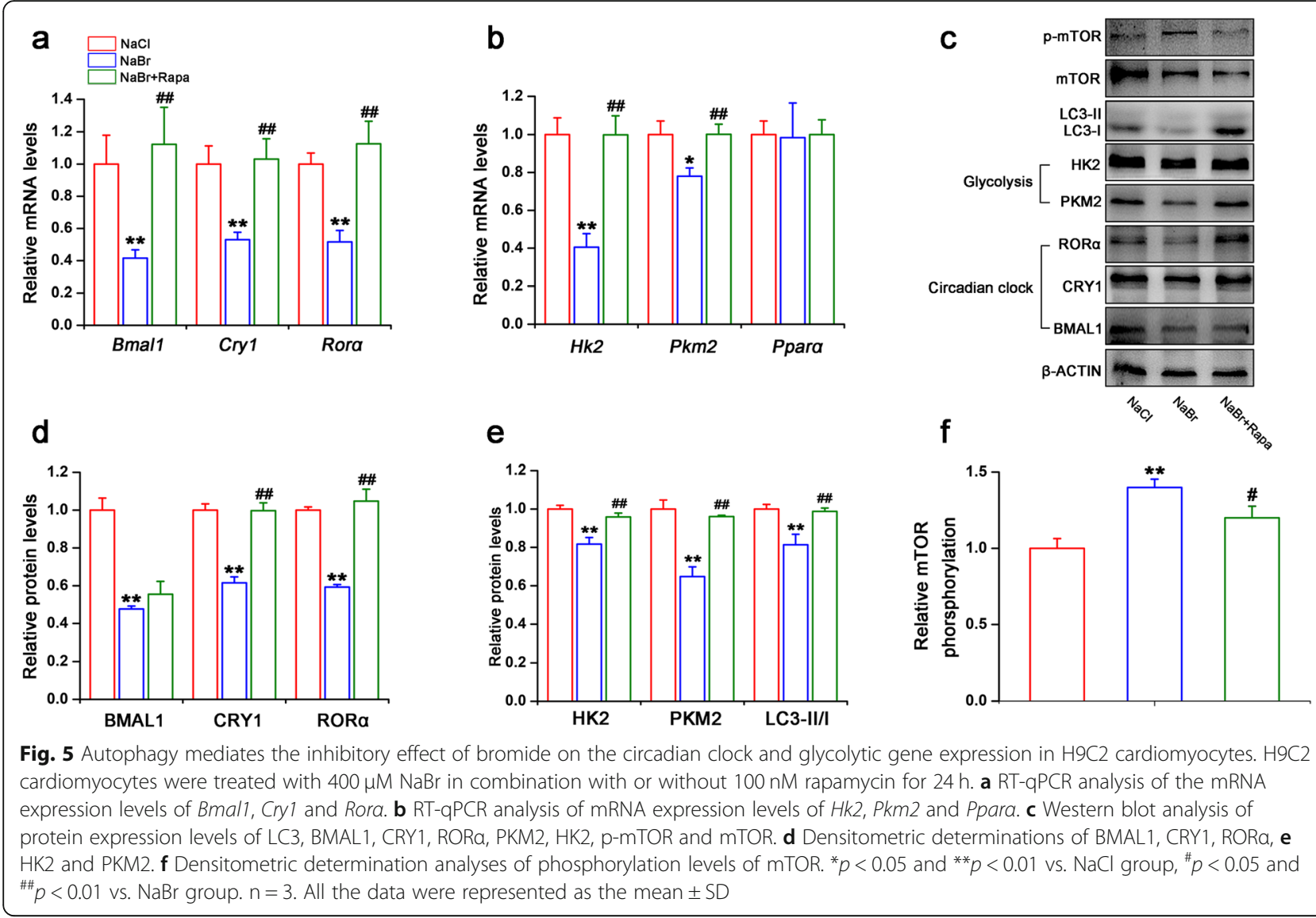

by the US National Institutes of Health (NIH publication No. 85-23, revised 1996) and was approved by the Laboratory Animal Care \& Use Committee at Nanjing Medical University (Permit number SYXK2018-0012). Briefly, newborn male Wistar rats (1-10 days old) were sacrificed by decapitation, hearts from rats were minced and dissociated with $0.25 \%$ trypsin and collagenase II. Dispersed cells were seeded at $10^{5}$ cells/well in 96-well plates with DMEM supplemented with $10 \%$ FBS and then cultured in a $5 \% \mathrm{CO}_{2}$ incubator at $37^{\circ} \mathrm{C}$.

\section{CCK-8 toxicity assay}

CCK-8 assay was performed to analyze potential toxic effects of sodium bromide (NaBr; Sigma-Aldrich, Germany) on $\mathrm{H} 9 \mathrm{C} 2$ cardiomyocytes. Briefly, $1 \times 10^{4}$ cells were seeded into each well of a 96-well plate and were cultured at $37^{\circ} \mathrm{C}$ overnight. After synchronization with serum-free DMEM, cells were transferred into $100 \mu \mathrm{L}$ serum-free DMEM containing either $\mathrm{NaBr}$ or equal amounts of sodium chloride $(\mathrm{NaCl}$, positive control) at indicated concentrations (ranging from $10 \mu \mathrm{M}$ to $600 \mu \mathrm{M}$ ) and incubated for another $24 \mathrm{~h}$. Then, $10 \mu \mathrm{L}$ CCK-8 reagent (Jiancheng, Nanjing, China) was added to each well and incubated at $37^{\circ} \mathrm{C}$ for $4 \mathrm{~h}$. Finally, a microplate reader was used to measure the absorbance at $450 \mathrm{~nm}$.

\section{Serum shock}

The media of confluent cultures was replaced with DMEM plus $50 \%$ horse serum. After $2 \mathrm{~h}$ shock, the cells were washed twice with PBS and incubated with serum-free DMEM containing $400 \mu \mathrm{M} \mathrm{NaBr}$ or $\mathrm{NaCl}$. Cell samples were collected at 4-h intervals. Total RNA was extracted and processed for reverse transcription-quantitative polymerase chain reaction (RT-qPCR) analysis.

\section{RT-qPCR analysis}

Total RNA from cells was isolated using Trizol reagent (Invitrogen, Carlsbad, California, USA), reverse transcribed with the PrimeScript RT reagent kit (Takara, Tokyo, Japan), and analyzed by real-time quantitative PCR using $2 \times$ ChamQ Universal SYBR qPCR Master Mix (Vazyme, Nanjing, China) according to the manufacturer's instructions. The Primers for rat GAPDH were included for normalization. A complete list of Primers was shown in Table S4 and synthesized by Generay Biotech Co., Ltd. (Shanghai, China). 


\section{Cardiomyocytes}

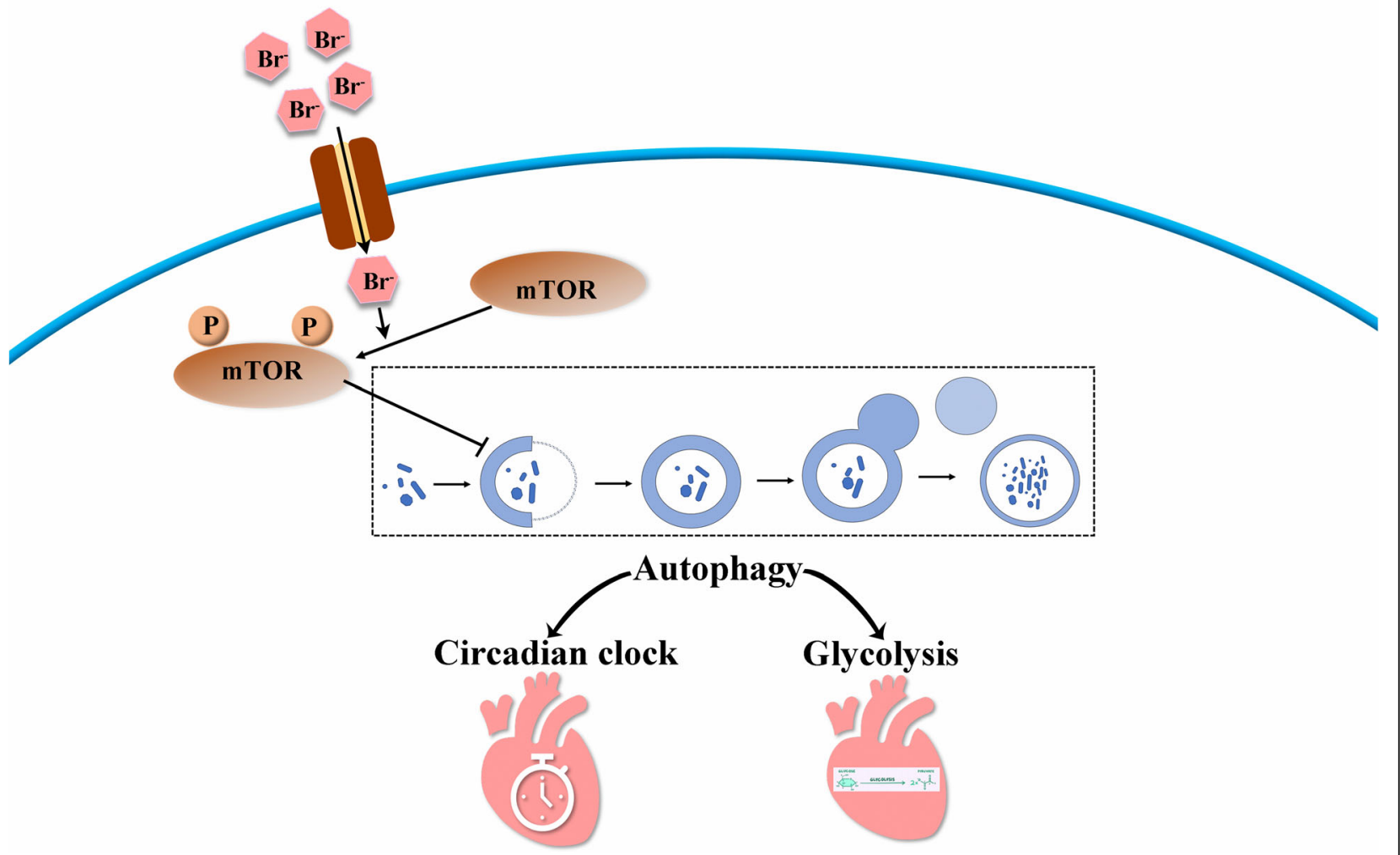

Fig. 6 The functional model illustrating the mechanism by which bromide dampens circadian and glycolytic gene expression and rhythmicity through inhibition of the autophagy in $\mathrm{H} 9 \mathrm{C} 2$ cardiomyocytes, highlighting the mediating role of mTOR in the bromide signal relay

\section{Western blotting analysis}

For protein analysis, cells were lysed in RIPA buffer. The protein concentration was quantified with a BCA Protein Quantitation Assay Kit (Beyotime Biotech., Shanghai, China). Equal amounts of protein were loaded and separated by $10 \%$ SDS-PAGE and then transferred onto a PVDF membrane (Millipore Corp., Billerica, MA, USA). The membranes were incubated overnight with appropriate primary antibodies at $4{ }^{\circ} \mathrm{C}$. Bound antibodies were then visualized using horseradish peroxidase-conjugated secondary antibodies. A quantitative analysis was performed by using ImageJ software (U.S. National Institutes of Health). For the antibody information, the antibodies against CRY1, HK2 and PKM2 were purchased from Proteintech (Chicago, IL, USA). Anti-ROR $\alpha$ were obtained from Santa Cruz Biotechnology (CA, USA). The antibodies against LC3II/I, BMAL1, ULK1 and ATG5 were purchased from Bioworld Technology, Inc. (Nanjing, China). The antibody against $\beta$-ACTIN was derived from Servicbio Technology Co., Ltd. (Wuhan, China). The secondary antibodies were obtained from Santa
Cruz Biotechnology (CA, USA). Uncropped images are shown in Fig. S5.

\section{Statistical analysis}

Groups of data were presented as the means \pm standard deviation (SD). Data were analyzed by using one-way ANOVA followed by Fisher's LSD post hoc test. Calculations were performed by using Origin 8 software (version 8.6, OriginLab, Northampton, MA, USA). A value of $P<0.05$ was considered statistically significant. Circadian variations, including amplitude andvphase shift, were calculated by fitting a cosine-wave equation $[\mathrm{y}=$ baseline $+($ Amplitude $\times \operatorname{Cos}(2 \times \pi \times(x$-phaseshift $) / 24)]$ on clock gene expression, with a fixed 24-h period (detailed data for the oscillation of clock genes were presented in Supplementary Table 2, 3 and 4). Time series data were analyzed using one-way or two-way ANOVA followed by Bonferroni's post hoc test. A $p$-value of less than 0.05 was considered to be statistically significant. Unless otherwise indicated, the statistics was performed using Student's t-test when only two groups were compared. 


\section{Supplementary information}

Supplementary information accompanies this paper at https://doi.org/10. 1186/s12860-020-00289-8.

Additional file 1: Figure S1. Bromide does not affect survival and apoptosis of rat neonatal primary cardiomyocytes. Rat neonatal primary cardiomyocytes were treated with $\mathrm{NaBr}$ at indicated doses for $24 \mathrm{~h}$. (a) Cell viability was assessed by CCK-8 assay.

Additional file 2: Figure S2. Bromide regulates clock gene expression in $\mathrm{H} 9 \mathrm{C} 2$ cardiomyocytes. $\mathrm{H} 9 \mathrm{C} 2$ cardiomyocytes were incubated with $\mathrm{NaBr}$ at indicated doses for $24 \mathrm{~h}$. (a) RT-qPCR analysis of the mRNA expression levels of Clock, Per1, Per2, Cry1, Rev-erba, Rev-erb $\beta$ and Dbp. ${ }^{*} p<0.05$ and ${ }^{* *} p<0.01$ vs. $\mathrm{NaCl}$ group. $n=3$. All the data were represented as the mean \pm SD.

Additional file 3: Figure S3. QX77 partially reversed the inhibitory effect of $\mathrm{NaBr}$ on the mRNA and protein expression levels of clock genes and glycolytic genes. $\mathrm{H} 9 \mathrm{C} 2$ cardiomyocytes were treated with $400 \mu \mathrm{M}$ $\mathrm{NaBr}$ in combination with or without $10 \mu \mathrm{M}$ OX77 for $24 \mathrm{~h}$. (a) RT-qPCR analysis of the mRNA expression levels of Bmal1, Cryl and Rora. (b) RTqPCR analysis of mRNA expression levels of Hk2, P km2 and Ppara. (c) Western blot analysis of protein expression levels of BMAL1, CRY1, RORa, PKM2 and HK2. (d) Densitometric determinations of BMAL1, CRY1, RORa, (e) HK2 and PKM2. ${ }^{*} p<0.05$ and ${ }^{* *} p<0.01$ vs. NaCl group, ${ }^{*} p<0.05$ and ${ }^{\# \#} p<0.01$ vs. $\mathrm{NaBr}$ group. $n=3$. All the data were represented as the mean \pm SD.

Additional file 4: Figure S4. $\mathrm{H} 9 \mathrm{C} 2$ cardiomyocytes were susceptible to $\mathrm{H}_{2} \mathrm{O}_{2}$ stimuli after treatment of $\mathrm{NaBr}$. $\mathrm{H} 9 \mathrm{C} 2$ cardiomyocytes were treated with $\mathrm{NaBr}$ with or without $1 \mu \mathrm{M} \mathrm{H}_{2} \mathrm{O}_{2}$ for $24 \mathrm{~h}$. Cell viability was assessed by CCK-8 assay. ${ }^{* *} p<0.01$ vs. $\mathrm{NaCl}$ group, ${ }^{\# \#} p<0.01$ vs. $\mathrm{NaCl}$ plus $\mathrm{H}_{2} \mathrm{O}_{2}$ group. $n=3$. All the data were represented as the mean $\pm S D$.

Additional file 5: Figure S5. Uncropped images of the blots included in the Figures.

Additional file 6: Table S1. Calculations of Amplitude and Phase shift in Fig. 2. Table S2. Calculations of Amplitude and Phase shift in Fig. 3.

Table S3. Calculations of Amplitude and Phase shift in Fig. 4. Table S4. The list of primer sequences for qPCR analysis.

\section{Abbreviations}

CCK-8: Cell counting kit-8; NaBr: Sodium bromide; NaCl: Sodium chloride; GAPDH: Glyceraldehyde-3-phosphate dehydrogenase; CRY: Cryptochrome; HK2: Hexokinase 2; PKM2: Pyruvate kinase M 2; RORa: RAR-related orphan receptor a; BMAL1: Brain and muscle arnt-Like Protein 1; ULK1: Unc-51 like kinase 1; ATG5: Autophagy related 5; PPARa: Peroxisome proliferator activated receptor $a$; Garabapl1: GABA(A) receptor associated protein like 1; mTOR: Mechanistic target of rapamycin kinase; Clock: Circadian locomotor output cycles kaput; Per: Period; Rev-erb: Nuclear receptor subfamily 1, group D; Dbp: D site albumin promoter binding protein

\section{Acknowledgements}

Not applicable.

\section{Authors' contributions}

YCJ, YG and XWZ designed the study. YCJ, YG, HX, WTY, XYT, XFZ and XJX performed the experiments and analyzed the data. $Y C J$ and XWZ wrote the manuscript and critically revised it. All authors read and approved the final manuscript.

\section{Funding}

This project was funded by Jiangsu Provincial Youth Medical Key Talents Project (QNRC2016431), the Research Fund for the Technology Development Project of Nanjing Medical University (grant no. NMUB2018148). The funders had no role in study design, data collection and analysis, decision to publish, or preparation of the manuscript.

\section{Availability of data and materials}

Data and materials used during the current study are available from the corresponding author on reasonable request.

\section{Ethics approval and consent to participate}

All procedures were approved by the Laboratory Animal Care \& Use Committee at Nanjing Medical University (Permit number SYXK2018-0012).

\section{Consent for publication}

Not applicable

\section{Competing interests}

The authors declare that they have no competing interests.

Received: 31 October 2019 Accepted: 9 June 2020

Published online: 19 June 2020

\section{References}

1. Jankowska EA, Rozentryt P, Witkowska A, Nowak J, Hartmann O, Ponikowska B, Borodulin-Nadzieja L, Banasiak W, Polonski L, Filippatos G. Iron deficiency: an ominous sign in patients with systolic chronic heart failure. Eur Heart J. 2010;31(15):1872-80.

2. Fukunaka A, Fujitani Y. Role of zinc homeostasis in the pathogenesis of diabetes and obesity. Int J Mol Sci. 2018;19(2):476.

3. Myint ZW, Oo TH, Thein KZ, Tun AM, Saeed H. Copper deficiency anemia. Ann Hematol. 2018;97(9):1527-34.

4. Soltermann F, Abegglen C, Gotz C, Von Gunten U. Bromide sources and loads in Swiss surface waters and their relevance for bromate formation during wastewater Ozonation. Environ Sci Technol. 2016;50(18):9825-34.

5. Holtkamp M. Other less commonly used antiepileptic drugs (Chapter 54). In: Simon S, Emilio P, Jerome E, editors. The treatment of epilepsy. 4th ed. Chichester: Wiley; 2015. p. 689-700.

6. Halpin DM, Kaplan AG, Russell RK. Why choose tiotropium for my patient? A comprehensive review of actions and outcomes versus other bronchodilators. Respir Med. 2017;128:28-41.

7. Shi Y, Zhang W, Cheng Y, Liu C, Chen S. Bromide alleviates fatty acidinduced lipid accumulation in mouse primary hepatocytes through the activation of PPARa signals. J Cell Mol Med. 2019;23(6):4464-74.

8. Docherty J, McGrath J. Sympathomimetic effects of pancuronium bromide on the cardiovascular system of the pithed rat: a comparison with the effects of drugs blocking the neuronal uptake of noradrenaline. $\mathrm{Br} J$ Pharmacol. 1978;64(4):589-99.

9. Anderson MP, Gregory RJ, Thompson S, Souza DW, Paul S, Mulligan RC, Smith AE, Welsh MJ. Demonstration that CFTR is a chloride channel by alteration of its anion selectivity. Science. 1991;253(5016):202-5.

10. Gadsby DC, Nagel G, Hwang T. The CFTR chloride channel of mammalian heart. Annu Rev Physiol. 1995;57(1):387-416.

11. Gubin D, Weinert D, Rybina S, Danilova L, Solovieva S, Durov A, Prokopiev N, Ushakov P. Activity, sleep and ambient light have a different impact on circadian blood pressure, heart rate and body temperature rhythms. Chronobiol Int. 2017;34(5):632-49.

12. Chellappa SL, Vujovic N, Williams JS, Scheer FA. Impact of circadian disruption on cardiovascular function and disease. Trends Endocrinol Metabol. 2019;30(10):767-79.

13. Young ME, Brewer RA, Peliciari-Garcia RA, Collins HE, He L, Birky TL, Peden BW, Thompson EG, Ammons B-J, Bray MS. Cardiomyocyte-specific BMAL1 plays critical roles in metabolism, signaling, and maintenance of contractile function of the heart. J Biol Rhythm. 2014;29(4):257-76.

14. Dong D, Li L, Gu P, Jin T, Wen M, Yuan C, Gao X, Liu C, Zhang Z. Profiling metabolic remodeling in PP2Aca deficiency and chronic pressure overload mouse hearts. FEBS Lett. 2015;589(23):3631-9.

15. Martino TA, Young ME. Influence of the cardiomyocyte circadian clock on cardiac physiology and pathophysiology. J Biol Rhythm. 2015;30(3):183-205.

16. Kaur J, Debnath J. Autophagy at the crossroads of catabolism and anabolism. Nat Rev Mol Cell Biol. 2015;16(8):461.

17. Corrigan FM, Skinner ER, Maclntyre F, ljomah G, Holliday J, Horrobin DF, Ward NI. Plasma bromine concentrations and lipid profiles. Clin Chim Acta. 1991;204(1-3):301-4.

18. Canavese C, De Costanzi E, Stratta P, Sabbioni E. A role for bromine deficiency in sleep disturbances of long-term dialysis patients. Am J kidney Dis. 2006;48(6):1018-9 author reply 1019.

19. Flury M, Papritz A. Bromide in the natural environment: occurrence and toxicity. J Environ Qual. 1993;22(4):747-58. 
20. Lawrence JF, Chadha RK, Iverson F, McGuire P, Conacher HB. Brominated fatty acid distribution in tissues and fluids of rats fed brominated vegetable oils. Lipids. 1984;19(9):704-7.

21. Randow F, Münz C. Autophagy in the regulation of pathogen replication and adaptive immunity. Trends Immunol. 2012;33(10):475-87.

22. White $E$. The role for autophagy in cancer. J Clin Invest. 2015;125(1):42-6.

23. Xu X, Kobayashi S, Chen K, Timm D, Volden P, Huang Y, Gulick J, Yue Z, Robbins J, Epstein PN. Diminished autophagy limits cardiac injury in mouse models of type 1 diabetes. J Biol Chem. 2013;288(25):18077-92.

24. Lavandero S, Chiong M, Rothermel BA, Hill JA. Autophagy in cardiovascular biology. J Clin Invest. 2015;125(1):55-64.

25. Chen X, Xu J, Liu D, Sun Y, Qian G, Xu S, Gan F, Pan C, Huang K. The aggravating effect of selenium deficiency on $\mathrm{T}-2$ toxin-induced damage on primary cardiomyocyte results from a reduction of protective autophagy. Chem Biol Interact. 2019:300:27-34

26. Toledo M, Batista-Gonzalez A, Merheb E, Aoun ML, Tarabra E, Feng D, Sarparanta J, Merlo P, Botrè F, Schwartz GJ. Autophagy regulates the liver clock and glucose metabolism by degrading CRY1. Cell Metabol. 2018;28(2): 268-81 e264.

27. Lu F, Tian Z, Zhang W, Zhao Y, Li H, Ren H, Zheng H, Liu C, Hu G, Tian Y. Calcium-sensing receptors regulate cardiomyocyte $\mathrm{Ca} 2+$ signaling via the sarcoplasmic reticulum-mitochondrion interface during hypoxia/ reoxygenation. J Biomed Sci. 2010;17(1):50.

\section{Publisher's Note}

Springer Nature remains neutral with regard to jurisdictional claims in published maps and institutional affiliations.

Ready to submit your research? Choose BMC and benefit from:

- fast, convenient online submission

- thorough peer review by experienced researchers in your field

- rapid publication on acceptance

- support for research data, including large and complex data types

- gold Open Access which fosters wider collaboration and increased citations

- maximum visibility for your research: over $100 \mathrm{M}$ website views per year

At $\mathrm{BMC}$, research is always in progress.

Learn more biomedcentral.com/submissions 